\title{
Catalytic decoloration of methyl orange solution by nanoporous metals
}

\section{AUTHOR(S):}

Hakamada, Masataka; Hirashima, Fumi; Mabuchi, Mamoru

\section{CITATION:}

Hakamada, Masataka ... [et al]. Catalytic decoloration of methyl orange solution by nanoporous metals. Catalysis Science and Technology 2012, 2(9): 1814-1817

\section{ISSUE DATE:}

2012-09-01

URL:

http://hdl.handle.net/2433/237655

\section{RIGHT:}

This is the accepted manuscript of the article, which has been published in final form at

https://doi.org/10.1039/c2cy20218b; The full-text file will be made open to the public on 28 May 2013 in accordance with publisher's 'Terms and Conditions for Self-Archiving':; この論文は出版社版でありません。引用の際には出版社版 をご確認ご利用ください。; This is not the published version. Please cite only the published version. 


\title{
Catalytic decoloration of methyl orange solution by nanoporous metals
}

\author{
Masataka Hakamada, ${ }^{* a}$ Fumi Hirashima ${ }^{a}$ and Mamoru Mabuchi ${ }^{a}$ \\ Received (in $X X X, X X X)$ th $X X X X X X X X X 20 X X$, Accepted Xth $X X X X X X X X X 20 X X$ \\ DOI: 10.1039/b000000x
}

\begin{abstract}
5 Nanoporous Au exhibit catalytic degradation of methyl orange (MO) solution while counterpart bulk Au does not. Other nanoporous metals such as Pd and $\mathrm{Ni}$ also exhibited the catalytic MO degradation. Because the degradation occurred under dark conditions, it is clearly distinguished from ${ }_{10}$ photocatalytic degradation conventionally observed in $\mathrm{TiO}_{2}$ and $\mathrm{ZnO}$.
\end{abstract}

The toxic pollution caused by azo dyes in the environment has attracted much attention recently. Various catalysts and photocatalysts have been investigated to remove such 15 environment pollutants. ${ }^{1-4}$ Nanosized materials such as nanoparticles, nanotubes and their composites are promising due to their larger surface-to-volume ratios and subsequent increase of reaction rate in catalysis ${ }^{5}$ and photocatalysis. ${ }^{6}$

On the other hand, nanoporous metals with nanosized pores 20 and ligaments are emerging nanostructured materials and can be readily fabricated by dealloying (selective dissolution of less noble metals from binary alloys). ${ }^{7}$ The open-cell nanoporous structure of metals offers many interesting properties, such as catalytic, $^{8-13}$ electrical, ${ }^{14}$ and piezoelectric properties. ${ }^{15,16}$ 25 Nanoporous metals have surface atomic irregularities such as defects and strain, which cause these peculiar properties to be distinguished from other nanomaterials. ${ }^{17,18}$

Several studies have reported that nanoporous $\mathrm{Au}$ exhibits catalysis during the oxidation of $\mathrm{CO}^{8-12}$ and methanol, ${ }^{13}$ while its 30 counterpart, bulk Au without a porous structure, does not. In the present work, we show the catalytic degradation of a dye solution by nanoporous $\mathrm{Au}$, which is distinguished from the conventional photocatalytic effect known in semiconductor oxides such as $\mathrm{TiO}_{2}$ and $\mathrm{ZnO}$.

35 Nanoporous $\mathrm{Au}$ was fabricated by dealloying a $\mathrm{Au}_{0.3} \mathrm{Ag}_{0.7}$ sheet under various conditions of free and electrochemical corrosion. Detailed experimental methods are described in the Supporting Information. Figs. $1 \mathrm{a}-\mathrm{c}$ are scanning electron micrographs of fabricated nanoporous $\mathrm{Au}$. The average ligament 40 size and pore diameter were larger in the sample fabricated by free corrosion at room temperature than in the two other nanoporous $\mathrm{Au}$, as summarized in Table 1. Smaller pores and ligaments are well correlated to higher roughness factors $(R)$ determined by cyclic voltammetry in $0.1 \mathrm{~mol} / \mathrm{L} \mathrm{H}_{2} \mathrm{SO}_{4} \cdot{ }^{19}$ These 45 trends are in agreement with the previous studies on nanoporous $\mathrm{Au}{ }^{20,21}$ For comparison, pure $\mathrm{Au}, \mathrm{Au}_{0.7} \mathrm{Ag}_{0.3}$ and $\mathrm{Au}_{0.3} \mathrm{Ag}_{0.7}$ rolled sheets was also prepared as bulk materials.

Methyl orange (MO), a typical azo used in the textile industry,

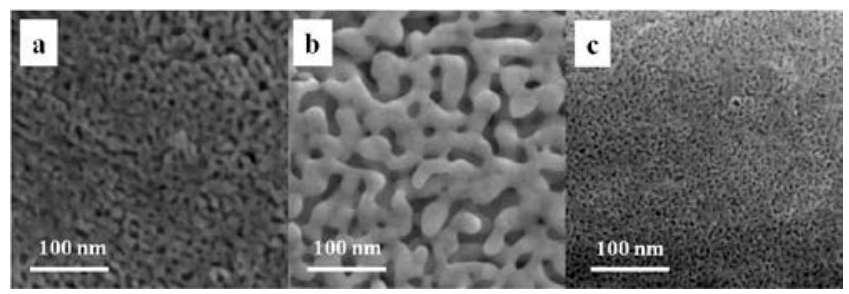

50 Fig. 1 SEM images of nanoporous Au samples. (a) Sample 1 made by free corrosion at 263 K. (b) Sample 2 made by free corrosion at 298 K. (c) Sample 3 made by electrochemical dealloying.

is very stable and is commonly used as the probe for evaluating photocatalysts; ${ }^{6,22}$ thus the catalytic activities of the nanoporous ${ }_{55} \mathrm{Au}$ for degradation of the MO was assessed at room temperature (= $298 \mathrm{~K}$ ). Different samples (with nominal exposed areas of 2 $\left.\mathrm{cm}^{2}\right)$ were immersed into $5 \mathrm{ml}$ of MO solution $\left(2 \times 10^{-5} \mathrm{~mol} / \mathrm{L}\right)$. The experiments were conducted under a dark condition to distinguish the MO decrease from photocatalysis. The 60 concentration of MO in the solution as a function of soaking time was measured by monitoring the absorbance of the MO at its absorption maximum wavelength $\left(\lambda_{\max }=466.5 \mathrm{~nm}\right)$ using a UVVis spectrometer (UV-2100 Shimadzu, Japan). For comparison, bulk $\mathrm{TiO}_{2}$ and $\mathrm{ZnO}$ sheets have been subjected to the $\mathrm{MO}$ 65 decoloration tests under a dark condition.

Time variation of the MO concentration after sample immersion is shown in Fig. 2a. Nanoporous Au (Samples 1-3) significantly reduced MO concentration, whereas bulk Au, bulk $\mathrm{Au}_{0.3} \mathrm{Ag}_{0.7}$, and bulk $\mathrm{Au}_{0.7} \mathrm{Ag}_{0.3}$ had no distinguishable effect on 70 the MO concentration. After 30-h immersion of the nanoporous Au with ligaments and a pore size of less than $10 \mathrm{~nm}$ (Samples 1 and 3), the MO concentration became negligible. This is also demonstrated in Fig. 2b, which shows the appearance of the MO solution after the 30-h immersion. On the other hand, $\mathrm{TiO}_{2}$ and ${ }_{75} \mathrm{ZnO}$ photocatalytic sheets were found not to decrease the MO concentration (Fig. S1), because the tests were carried out under a dark condition with no light irradiation.

The reaction kinetic constants $(k)$ are estimated assuming a first-order reaction, where the assumption is reasonably accepted 80 by the logarithmic plots of the results (Fig. S2). The results are summarized in Table 2, where the values of $k$ divided by the roughness factor are also shown. Values of $k$ for Samples 1 and 3 are higher than that in Sample 2 with larger ligaments. This suggests that the MO concentration quickly decreases in the 85 presence of nanoporous Au with small ligaments. Moreover, the values of $k / R$ for Samples 1 and 3 are also larger than that in 


\section{Cite this: DOI: 10.1039/coxxooooox}

www.rsc.org/xxxxxx

ARTICLE TYPE

Table 1 Nanoporous Au and bulk Au samples subjected to decoloration of methyl orange (MO) solution.

\begin{tabular}{|c|c|c|c|c|c|}
\hline Sample No. & Specification $^{a}$ & $\begin{array}{c}\mathrm{Au}: \mathrm{Ag} \\
\text { (atomic \%) }\end{array}$ & $\begin{array}{c}\text { Ligament diameter, } \\
d_{\mathrm{L}}(\mathrm{nm})\end{array}$ & $\begin{array}{c}\text { Pore diameter, } \\
d_{\mathrm{P}}(\mathrm{nm})\end{array}$ & Roughness factor, $R$ \\
\hline 1 & Nanoporous Au (free corrosion at $263 \mathrm{~K}$ ) & $82: 18$ & 7.6 & 8.4 & 310 \\
\hline 2 & Nanoporous Au (free corrosion at $298 \mathrm{~K}$ ) & $92: 08$ & 21 & 18 & 270 \\
\hline 3 & Nanoporous Au (electrochemical dealloying) & $81: 19$ & 5.4 & 5.2 & 430 \\
\hline 4 & Bulk Au & $100: 0$ & - & - & - \\
\hline 5 & Bulk $\mathrm{Au}_{0.7} \mathrm{Ag}_{0.3}$ & $70: 30$ & - & - & - \\
\hline 6 & Bulk $\mathrm{Au}_{0.3} \mathrm{Ag}_{0.7}$ & $30: 70$ & - & - & - \\
\hline
\end{tabular}

${ }^{a}$ Footnote text.
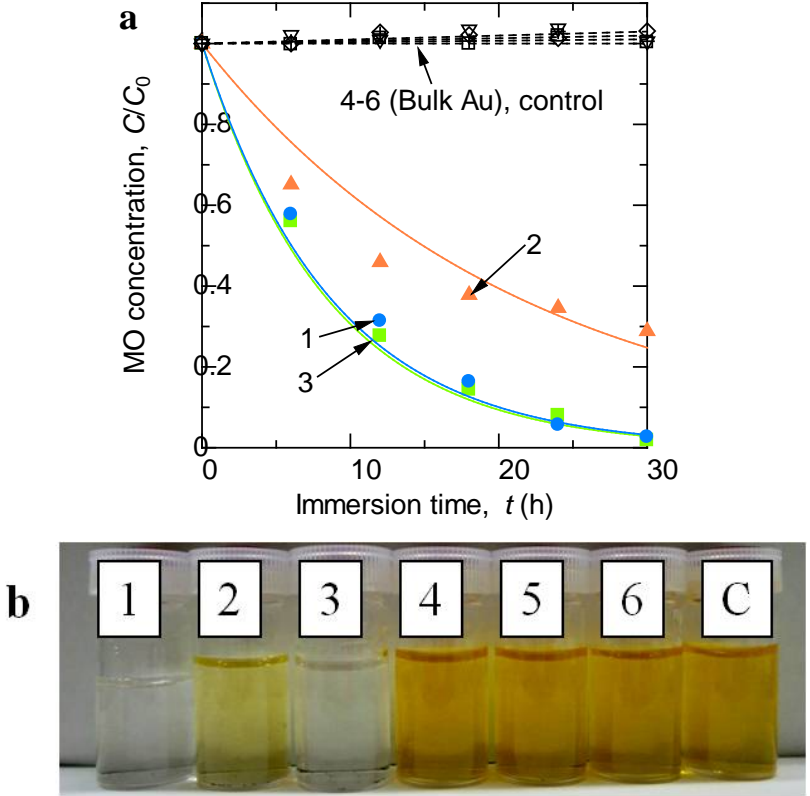

Fig. 2 (a) Time variation of MO concentration after the immersion of nanoporous Au and bulk Au samples. (b) Appearance of MO solution after the 30-h immersion of samples. The numbers indicate the Sample No. presented in Table 1. "C" means control experiment with no sample 10 immersion.

Table 2 Kinetic constants for decrease in MO concentration.

\begin{tabular}{ccc}
\hline Sample No. & $\begin{array}{c}\text { Reaction kinetic } \\
\text { constant, } k\left(\mathrm{~min}^{-1}\right)\end{array}$ & $k / R\left(\mathrm{~min}^{-1}\right)$ \\
\hline 1 & $2.0 \times 10^{-3}$ & $6.4 \times 10^{-6}$ \\
2 & $0.7 \times 10^{-3}$ & $2.6 \times 10^{-6}$ \\
3 & $2.1 \times 10^{-3}$ & $4.9 \times 10^{-6}$ \\
\end{tabular}

Sample 2, that is, smaller ligaments exhibited higher $k / R$. Hence, the decrease in MO concentration is not simply proportional to the surface area. Smaller ligaments enhanced the reaction not 15 merely due to the increase in surface area.

An additional set of experiments was conducted to confirm the catalytic decomposition of MO. Fig. 3 shows the UV-Vis spectra of the MO solution before and after a 1-week immersion of
Sample 1. The initial concentration of MO was $1.5 \times 10^{-4} \mathrm{~mol} / \mathrm{L}$ 20 in this experiment. After the immersion of Sample 1, the absorbance at the visible light wavelength range (400-700 nm) disappeared, which corresponds with the decoloration of the MO solution. However, the absorbance in an ultraviolet region of $\lambda<$ $220 \mathrm{~nm}$ increased after the immersion. The absorbance of the azo 25 dye solution in the ultraviolet region is closely related to a short conjugated system of the organic molecule and typical of phenyl rings, while that in the visible light wavelength range is caused by azo group $(-\mathrm{N}=\mathrm{N}-)$. ${ }^{23} \mathrm{MO}$ contains two phenyl rings bridged by an azo group in its chemical structure; therefore it is surmised 30 that MO decomposed to single phenyl ring compounds in the presence of nanoporous $\mathrm{Au}$.

High-performance liquid chromatography (HPLC) studies using an instrument equipped with a UV-Vis photodiode array detector were also conducted using a reverse-phase setup. Fig. 4 35 shows the resulting chromatograms of the MO solution before and after the 1-week immersion of Sample 1. The initial MO solution showed single peaks for both wavelengths of $\lambda=210$ and $450 \mathrm{~nm}$ at the same retention times $\left(t_{\mathrm{R}}\right)$ of $9.9 \mathrm{~min}$, which suggests that these peaks are characteristic of MO. As for $\lambda=450$ $40 \mathrm{~nm}$, the peak intensity at $t_{\mathrm{R}}=9.9$ min significantly decreased to a concentration order of ppm after the sample immersion (note that the intensity is magnified by a factor of 200 in Figure $4 \mathrm{~b}$ for $\lambda=$ $450 \mathrm{~nm}$ ). Several peaks at $t_{\mathrm{R}}=7.6$ and $8.8 \mathrm{~min}$ were also detected after the immersion. Furthermore, as for $\lambda=210 \mathrm{~nm}$, the peak 45 position remarkably shifted to shorter $t_{R}$, accompanied with an increased peak intensity. It is generally accepted that the highlypolarized state of the analyzed compounds leads to shorter $t_{\mathrm{R}}$ in a reverse-phase HPLC. Hence, the polarity of the products in the solution after the immersion of nanoporous $\mathrm{Au}$ is higher than in so the initial MO.

Furthermore, X-ray photoelectron spectroscopy on the sample 1 before and after the immersion was conducted and the results are shown in Fig. S5. The Au $4 \mathrm{f}$ peaks were not shifted by the decoloration; thus the possibility of Au complex formation with 55 the dye is eliminated.

Figures 3 and 4 demonstrate that nanoporous $\mathrm{Au}$ can catalytically reduce the MO concentration by chemical decomposition of MO and not by the simple adsorption of MO on the surface of the nanoporous $\mathrm{Au}$, such as reported in the case of 


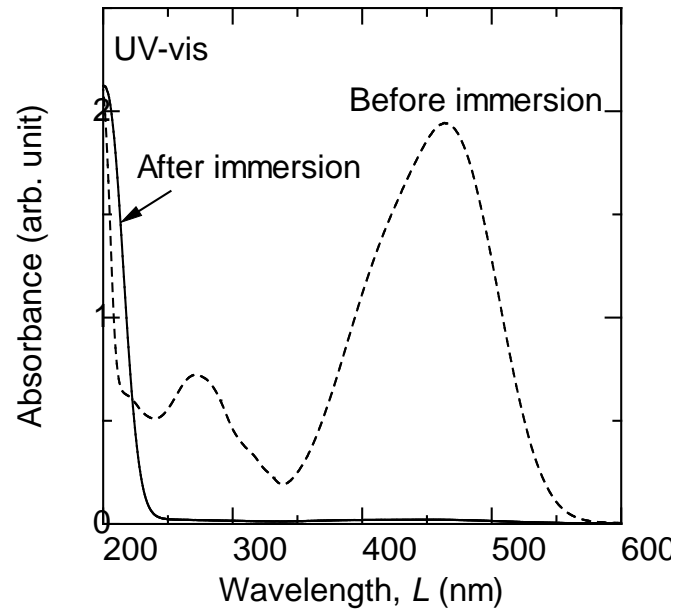

Fig. $3 \mathrm{UV}$-Vis spectra of the MO solution before and after 1-week immersion of Sample 1 at room temperature.

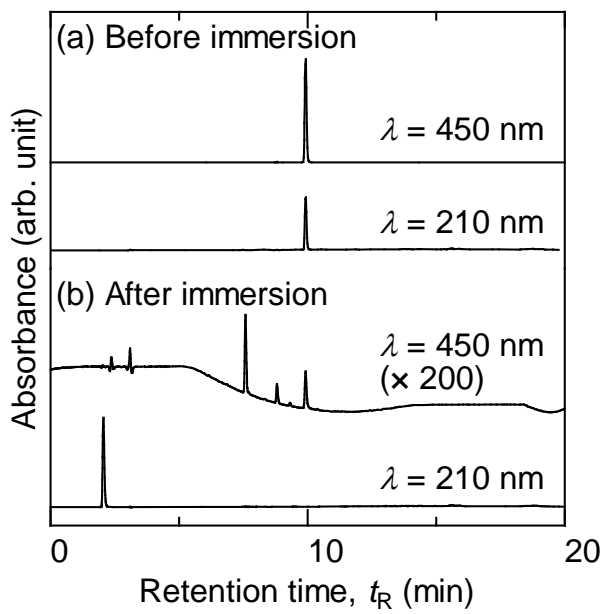

5 Fig. 4 Chromatogram of MO solution before and after 1-week immersion of Sample 1 at room temperature.

mesoporous iron oxides. ${ }^{24}$ Nanoporous Au catalytically breaks the azo group in MO but keeps single phenyl groups unchanged. This is quite different from the situation in photocatalysts where 10 excited radical ion attacks a compound to be decomposed to, in many cases, $\mathrm{CO}_{2}$ and $\mathrm{H}_{2} \mathrm{O}$. Au had long been regarded as a poorly active catalyst until Haruta et al. reported that $\mathrm{Au}$ nanoparticles deposited on metal oxides exhibit surprisingly high catalytic activity for CO oxidation at a temperature as low as 200 ${ }_{15} \mathrm{~K} .{ }^{25,26}$ Since then, many researchers have proposed mechanisms for the catalysis of deposited Au nanoparticles. ${ }^{27-30}$ One of those reasons is the effect of step and strain in Au. Mavrikakis et al. ${ }^{31}$ have shown that extensive strain can increase the reactivity of $\mathrm{Au}$ surfaces. The latter has been experimentally reported for small $20 \mathrm{Au}$ particles (less than $4 \mathrm{~nm}$ in size) epitaxially grown on $\mathrm{MgO}$ (100), where a $2.9 \%$ increase of the lattice spacing, compared to the bulk value, was measured. ${ }^{32}$ By contrast, surface strain as large as $\pm 5 \%$ has been reported in nanoporous metals. ${ }^{17}$ Thus, it is suggested that nanoporous structures can offer more complex 25 surface defects than nanoparticles, and possibly increase the reactivity of Au.

The catalytic activity of nanoporous Au toward CO oxidation

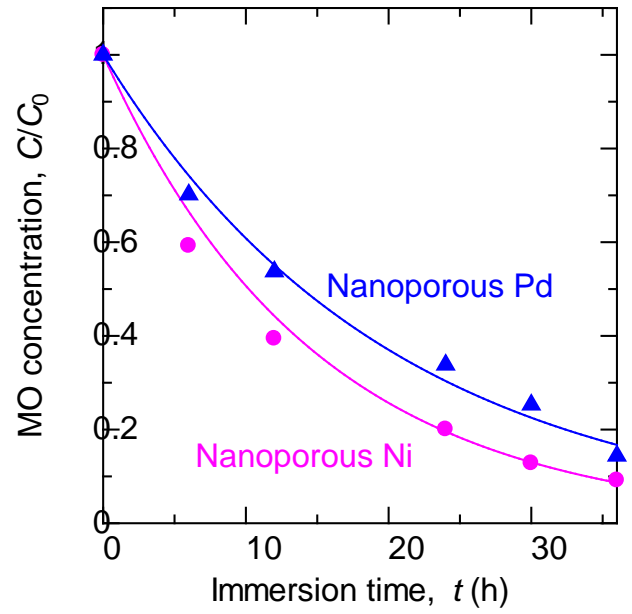

Fig. 5 Time variation of MO concentration after the immersion of nanoporous $\mathrm{Pd}$ and $\mathrm{Ni}$.

has been reported. ${ }^{8-12}$ The researchers have investigated in some detail two effects which might make Au surfaces more chemically reactive: (a) atomic defects and strain, ${ }^{8}$ and (b) residual Ag. ${ }^{10,11}$ During dealloying, Ag, even if removed almost 35 completely from the bulk, segregates to the surface and affects the surface properties. ${ }^{10,33,34}$ As shown above, the reactions of Sample 1 and Sample 3 (nanoporous Au including a large amount of Ag), were faster than that of Sample 2 (nanoporous Au including a lesser amount of Ag). However, the decrease in $\mathrm{MO}$ 40 concentration caused by Samples 5 and 6 (bulk $\mathrm{Au}_{0.7} \mathrm{Ag}_{0.3}$ and bulk Au0.3Ag0.7), as well as by Sample 4 (bulk $\mathrm{Au}$ ) has been negligibly detected. The role of residual Ag will be strictly confirmed by the control of residual $\mathrm{Ag}$ in nanoporous $\mathrm{Au}$ without other parameters change. ${ }^{35,36}$ Anyway, residual Ag 45 cannot simply explain the results for the present catalysis in Au.

Therefore, it is indicated that the defective and strained surface of the ligaments in nanoporous Au can increase the reactivity of the $\mathrm{Au}$ surfaces, and decrease the concentration of the MO solution. In the past, many reports have shown that 50 nanostructured $\mathrm{Au}$ has a wide variety of catalytic properties. ${ }^{27}$ However, there have been no reports to date for unsupported nanoporous $\mathrm{Au}$ exhibiting the catalytic degradation of complicated organic compounds such as azo dyes. The catalytic or photocatalytic degradation of such organic compounds as azo 55 dyes has required the use of an excess amount of oxidizing agents and irradiation of light. ${ }^{1-4,6,22}$ The present results also add the information on bond-breaking capacity of gold, which has been drawing much attention. ${ }^{37}$

On the other hand, the cleavage of azo bonding of $\mathrm{MO}$ 60 generate benzenesulfonic acid and $N, N$-dimethilaniline. The former is a relatively strong acid and the latter possibly has a cancerogenic aspect. We checked the $\mathrm{pH}$ of the solution before and after the immersion of nanoporous Au samples and found that the $\mathrm{pH}$ did not change. Thus the $\mathrm{MO}$, at the present 65 concentration at least, does not generate much benzenesulfonic acid after the decoloration. Further analyses are required to identify the toxicity of the reaction products.

The fabrication of nanoporous metals other than Au has also been reported. In this study, nanoporous Pd (ligament size: 20 $70 \mathrm{~nm}$ ) and $\mathrm{Ni}$ (ligament size: $9 \mathrm{~nm}$ ) are also fabricated by 
dealloying $^{38-41}$ (Fig. S3) and subjected to the MO degradation tests. As shown in Fig. 5, both nanoporous Pd and Ni clearly decreased the MO concentration in the surrounding solution. On the other hand, bulk Pd and Ni exhibited no decoloration of MO 5 solution (Fig. S4). Thus, nanoporous Pd and Ni also can decolor MO solutions.

In summary, the concentration of an $\mathrm{MO}$ solution has firmly decreased by the simple immersion of nanoporous metals. The comparative experiments indicated that the atomically defective 10 and strained surface, which are unique characteristics in nanoporous metals and alloys, have a significant effect on the MO decoloration. This catalysis needs no light irradiation unlike photocatalysts and is beneficial in the removal of textile industrial pollution, for example, in metallic channels which cannot permit 15 light irradiation.

\section{Acknowledgments}

M. H. is grateful for financial support by a JSPS Grant-in-Aid for Scientific Research (C) 21605013 for the measurement of MO concentration and a JSPS Grant-in-Aid for Young Scientists (B) 2024760572 for the preparation of nanoporous metals. The characterization of nanoporous Au is also supported by a JSPS Grant-in-Aid for Scientific Research (B) 23360305, for which M. M. is thankful. The authors thank Prof. T. Yao (Kyoto Univ.) and Prof. T. Yabutsuka (Kyoto Univ.) for their cooperation on the ${ }_{25}$ SEM observations and Dr. Y. Chino (National Institute of Advanced Industrial Science and Technology (AIST)) for the preparation of the starting alloys.

\section{Notes and references}

${ }^{a}$ Department of Energy Science and Technology, Graduate School of 30 Energy Science, Kyoto University, Yoshidahonmachi, Sakyo, Kyoto 6068501, Japan. Fax:+81 75753 5428; Tel: +81 75753 5427; E-mail: hakamada.masataka.3x@kyoto-u.ac.jp

$\dagger$ Electronic Supplementary Information (ESI) available: [Experimental details and additional results.]. See DOI: 10.1039/b000000x/

351 H. Lanchheb, E. Puzenat, A. Houas, M. Ksibi, E. Elaloui, C. Guilard and J. M. Herrmann, Appl. Catal. B: Environ. 2002, 39, 75.

2 M. R. Hoffmann, S. T. Martin, W. Choi and D. W. Bahnemann, Chem. Rev. 1995, 95, 69.

3 G. Ruppert, R. Bauer and G. Heisler, J. Photochem. Photobiol. A: $40 \quad$ Chem. 1993, 73, 75.

4 J. Fernandez, J. Bandara, A. Lopez, P. Buffat and J. Kiwi, Langmuir 1999, 15, 185

5 P. Vivek and S. V. Rajender, Green Chem. 2010, 12, 743.

6 C. W. Yen, M. A. Mahmoud and M. A. El-Sayed, J. Phys. Chem. A $45 \quad 2009,113,4340$.

7 J. Erlebacher, M. J. Aziz, A. Karma, N. Dimitrov and K. Sieradzki, Nature 2001, 410, 450.

8 V. Zielasek, B. Jürgens, C. Schulz, J. Biener, M. M. Biener, A. V. Hamza and M. Bäumer, Angew. Chem. Int. Ed. 2006, 45, 8241.

509 C. Xu, J. Su, X. Xu, P. Liu, H. Zhao, F. Tian and Y. Ding, J. Am. Chem. Soc. 2007, 129, 42.

10 S. Kameoka and A. P. Tsai, Catal. Lett. 2008, 121, 337.

11 A. Wittstock, B. Neumann, A. Schaefer, K. Dumbuya, C. Kubel, M. Biener, V. Zielasek, H. P. Steinruck, J. M. Gottfried, J. Biener, A. Hamza and M. Bäumer, J. Phys. Chem. C 2009, 113, 5593.

12 A. Wittstock, A. Wichmann, J. Biener and M. Bäumer, Faraday Discuss. 2011, 152, 87.

13 A. Wittstock, V. Zielasek, J. Biener, C. M. Friend and M. Bäumer, Science, 2010, 327, 319.

6014 A. K. Mishra, C. Bansal and H. Hahn, J. Appl. Phys. 2008, 103, 094308.
15 D. Kramer, R. N. Viswanath and J. Weissmüller, Nano Lett. 2004, 4, 793.

16 J. Biener, A. Wittstock, L. A. Zepeda-Ruiz, M. M. Biener, V. 65 Zielasek, D. Kramer, R. N. Viswanath, J. Weissmüller, M. Bäumer and A. V. Hamza, Nat. Mater. 2008, 8, 47.

17 M. Hakamada, H. Nakano, T. Furukawa, M. Takahashi and M. Mabuchi, J. Phys. Chem. C 2010, 114, 868.

18 M. Hakamada, M. Takahashi, T. Furukawa and M. Mabuchi, Appl. Phys. Lett. 2009, 94, 154105.

19 S. Trasatti and O. A. Petrii, J. Electroanal Chem. 1992, 327, 353.

20 M. Hakamada, Y. Chino and M. Mabuchi, Mater. Lett. 2010, 64, 2341.

21 Y. Ding, Y. J. Kim and J. Erlebacher, Adv. Mater. 2004, 16, 1897.

7522 I. M. Arabazis, T. Stergiopoulous, D. Andreeva, S. Kitova and S. G. Neophytides, J. Catal. 2003, 220, 127.

23 M. J. K. Thomas, Ultraviolet and Visible Spectroscopy, Analytical Chemistry by Open Learning, 2nd ed.; John Wiley \& Sons, Ltd., Chichester, UK, 1997, Ch. 5.

8024 S. Asuha, Y. W. Gao, W. Deligeer, M. Yu, B. Suyala and S. Zhao, J. Porous Mater. 2011, 18, 581.

25 M. Haruta, N. Yamada, T. Kobayashi and S. Iijima, J. Catal. 1989, 115, 301.

26 M. Haruta and M. Date, Appl. Catal. A-Gen. 2001, 222, 427.

8527 B. K. Min and C. M. Friend, Chem. Rev. 2007, 107, 2709.

28 R. Meyer, C. Lemire, S. K. Shaikhutdinov and H. J. Freund, Gold Bull. 2004, 37, 72.

29 H. Falsig, B. Hvolbæk, I. S. Kristensen, T. Jiang, T. Bligaard, C. H. Christensen and J. K. Nørskov, Angew. Chem. Int. Ed. 2008, 47, 4835.

30 J. K. Nørskov, T. Bligaard, B. Hvolbæk, F. Abild-Pedersen, I. Chorkendorffc and C. H. Christensend, Chem. Soc. Rev. 2008, 37, 2163.

31 M. Mavrikakis, P. Stoltze and J. K. Nørskov, Catal. Lett. 2000, 64, 101.

32 S. Giorgio, C. Chapon, C. R. Henry, G. Nihoul and J. M. Penisson, Philos. Mag. A 1991, 64, 87.

33 M. Hakamada, M. Takahashi, T. Furukawa, K. Tajima, K. Yoshimura, Y. Chino and M. Mabuchi, Phys. Chem. Chem. Phys. 2011, 13, 12277.

34 L. V. Moskaleva, S. Röhe, A. Wittstock, V. Zielasek, T. Klüner, K. M. Neyman and M. Bäumer, Phys. Chem. Chem. Phys. 2011, 13, 4529.

35 L. C. Wang, Y. Zhong, D. Widmann, J. Weissmüller and R. J. Behm, ChemCatChem 2012, 4, 251.

36 Y. Liu, S., Bliznakov and N. Dimitrov, J. Electrochem. Soc. 2010, 157, K168.

37 C. G. Freyschlag and R. J. Madix, Mater. Today 2011, 14, 134.

38 M. Hakamada and M. Mabuchi, Mater. Trans. 2009, 50, 431.

11039 M. Hakamada and M. Mabuchi, J. Alloy. Compd. 2009, 479, 326.

40 M. Hakamada and M. Mabuchi, J. Alloy. Compd. 2009, 485, 583.

41 M. Hakamada, K. Tajima, K. Yoshimura, Y. Chino, M. Mabuchi, J. Alloy. Compd. 2010, 494, 309. 


\title{
Electronic Supplementary Information
}

\section{Catalytic decoloration of methyl orange solution by nanoporous metals}

\author{
Masataka Hakamada*, Fumi Hirashima, Mamoru Mabuchi \\ Department of Energy Science and Technology, Graduate School of Energy Science, Kyoto \\ University, Yoshidahonmachi, Sakyo, Kyoto 606-8501, Japan
}

\section{Experimental details}

Fabrication of nanoporous $\mathrm{Au}$. A starting $\mathrm{Au}_{0.3} \mathrm{Ag}_{0.7}$ alloy sheet with thickness of $0.2 \mathrm{~mm}$ was fabricated by arc melting, homogenization annealing, cold rolling and cutting. Dealloying of the $\mathrm{Au}_{0.3} \mathrm{Ag}_{0.7}$ alloy sheet by free corrosion was conducted by immersion of the alloy sheet in 70 mass\% $\mathrm{HNO}_{3}$ at $263 \mathrm{~K}$ for $15 \mathrm{~h}$ (for Sample 1) and $298 \mathrm{~K}$ for $24 \mathrm{~h}$ (for Sample 2). Sample 3 was fabricated through electrochemical dealloying using the $\mathrm{Au}_{0.3} \mathrm{Ag}_{0.7}$ alloy sheet as a working electrode, that is, by electrolysis in $0.1 \mathrm{~mol} / \mathrm{L} \mathrm{HNO}_{3}$ for $10 \mathrm{~h}$ at a potentiostatic condition of $+1.1 \mathrm{~V}$ vs. a saturated calomel electrode (SCE) at room temperature.

Fabrication of nanoporous Pd. A starting $\mathrm{Pd}_{0.2} \mathrm{Co}_{0.8}$ alloy sheet was fabricated by arc melting, homogenization annealing, cold rolling and cutting. Electrolysis using the $\mathrm{Pd}_{0.2} \mathrm{Co}_{0.8}$ alloy sheet as a working electrode was conducted in $0.1 \mathrm{~mol} / \mathrm{L}_{2} \mathrm{SO}_{4}$ for $15 \mathrm{~h}$ at a potentiostatic condition at $+0.5 \mathrm{~V}$ vs. SCE at room temperature.

Fabrication of nanoporous Ni. A starting $\mathrm{Ni}_{0.3} \mathrm{Mn}_{0.7}$ alloy sheet was fabricated by arc melting, homogenization annealing, cold rolling and cutting. Electrolysis using the $\mathrm{Ni}_{0.3} \mathrm{Mn}_{0.7}$ alloy sheet as a working electrode was conducted in $1 \mathrm{~mol} / \mathrm{L}(\mathrm{NH} 4)_{2} \mathrm{SO}_{4}$ aqueous solution for $10 \mathrm{~h}$ at a potentiostatic condition at $-0.65 \mathrm{~V}$ vs. SCE at room temperature.

Characterization. Samples were observed using a field-emission scanning electron microscope (FE-SEM, SU6600 by Hitachi High-Technology Corp.) equipped with 
energy-dispersive X-ray spectroscopy (EDXS). The roughness factor of the nanoporous $\mathrm{Au}$ samples, which is the ratio of the electrochemically active surface area of nanoporous Au to that of smooth $\mathrm{Au}$, was estimated using the charge associated with the reduction of adsorbed oxygen during cyclic voltammetry in $0.1 \mathrm{~mol} / \mathrm{L} \mathrm{H}_{2} \mathrm{SO}_{4}$ (Trasatti and Petrii, J. Electroanal Chem. 327 (1992) 353).

High-performance liquid chromatography (HPLC). Target solutions $(10 \mu L)$ were analyzed using HPLC. Columns of Shim-pack VP-ODS with length of $150 \mathrm{~mm}$ and inner diameter of $4.6 \mathrm{~mm}$ were employed. The mobile phase was composed of two components; one is $10 \mathrm{mmol} / \mathrm{L}$ sodium phosphate buffer solution (pH 2.6) with $100 \mathrm{mmol} / \mathrm{L}$ sodium perchlorate and the other is acetonitrile. Gradient analysis at $313 \mathrm{~K}$ with a flow rate of $0.8 \mathrm{~mL} / \mathrm{min}$ was conducted according to the concentration schedule shown in Table S1.

Table S1. Concentration schedule for HPLC.

\begin{tabular}{cc}
\hline Time (min) & Concentration of acetonitrile (\%) \\
\hline 0.00 & 5 \\
10.00 & 70 \\
15.00 & 70 \\
15.01 & 5 \\
22.00 & Stop \\
\hline
\end{tabular}




\section{Additional results}

Immersion of $\mathrm{TiO}_{2}$ and $\mathrm{ZnO}$ sheets. Figure $\mathrm{S} 1$ shows the time variation of methyl orange (MO) concentration after immersion of $\mathrm{TiO}_{2}$ and $\mathrm{ZnO}$ sheets in the $\mathrm{MO}$ solution under a dark condition. No decrease in MO concentration was detected. This is due to the absence of light irradiation, because photocatalytic $\mathrm{TiO}_{2}$ and $\mathrm{ZnO}$ require light for decomposition of MO.

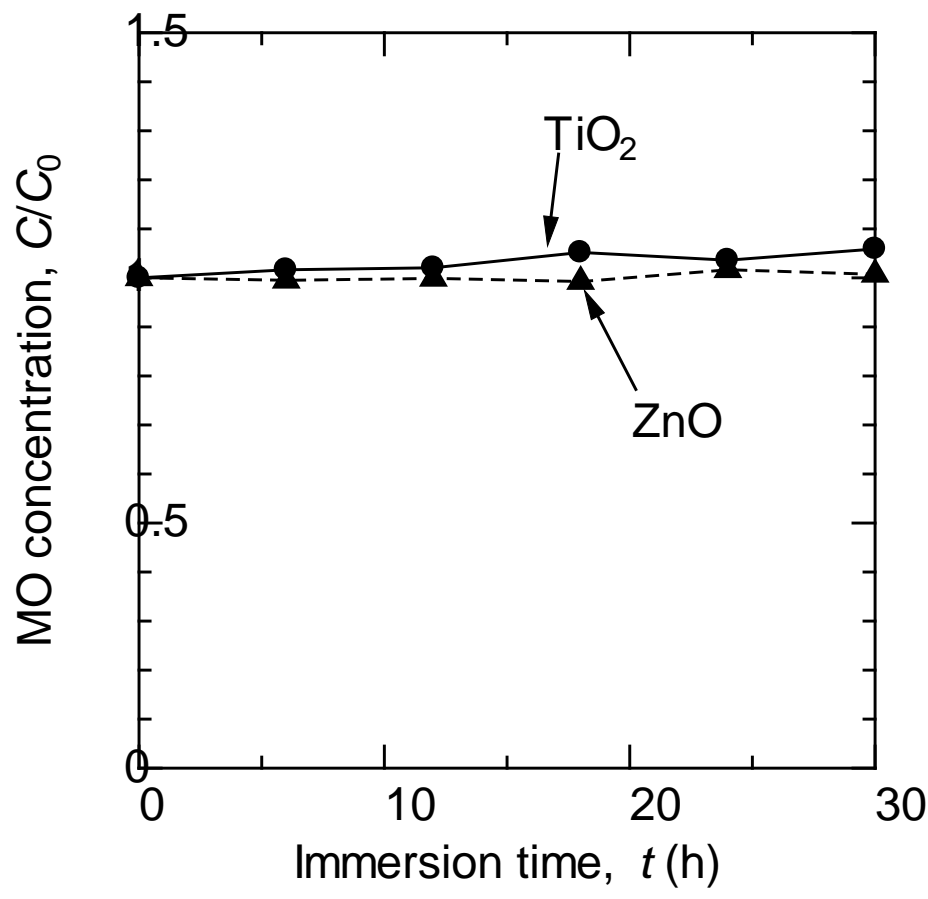

Figure S1. Time variation of methyl orange concentration after the immersion of $\mathrm{TiO}_{2}$ and $\mathrm{ZnO}$ sheets under a dark condition.

Logarithmic decrease in MO concentration by nanoporous Au. Figure S2 shows the logarithmic decrease in $\mathrm{MO}$ concentration after the immersion of nanoporous Au samples in the MO solution. The plots are well represented along the straight lines. This suggests that first-order reaction kinetics is reasonable for the MO decomposition. 


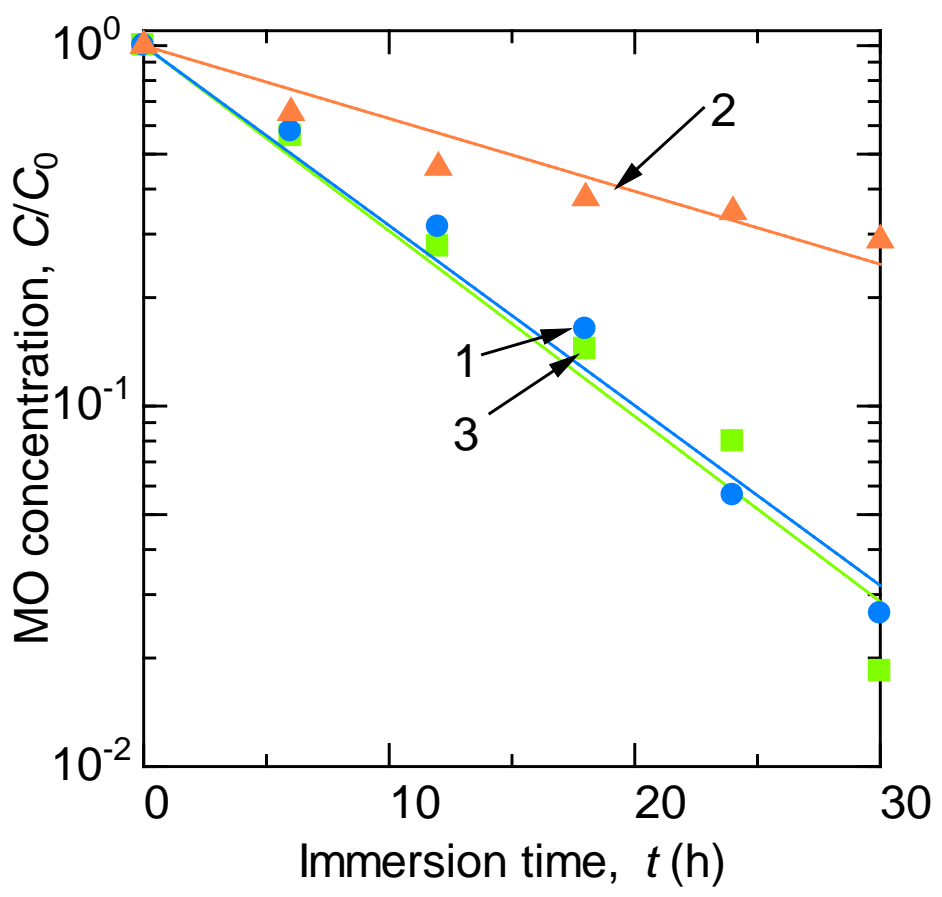

Figure S2. Time variation of MO concentration after the immersion of nanoporous $\mathrm{Au}$ samples in the MO solution measured according to a logarithmic scale. The numbers indicate the Sample No. presented in Table 1.

SEM images of nanoporous Pd and Ni. Figure S3 shows the SEM images of nanoporous Pd and Ni. Ligament sizes of 20 and $9 \mathrm{~nm}$ were observed in nanoporous Pd and Ni, respectively.

Nanoporous Pd

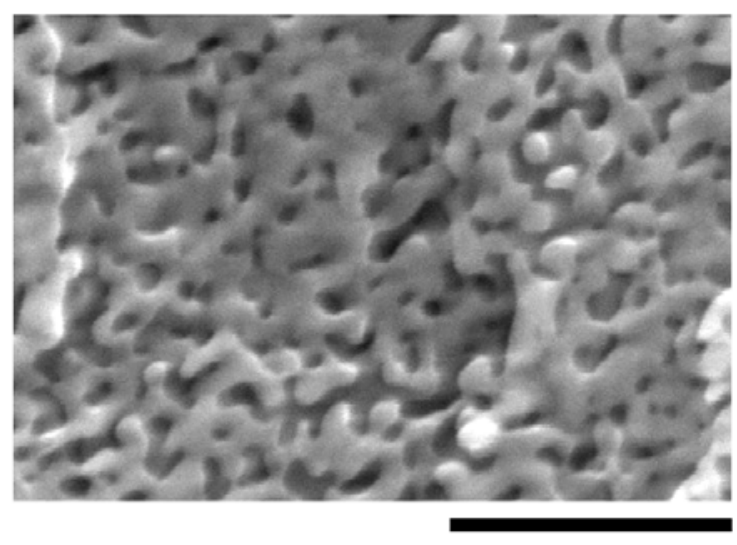

$200 \mathrm{~nm}$
Nanoporous $\mathrm{Ni}$

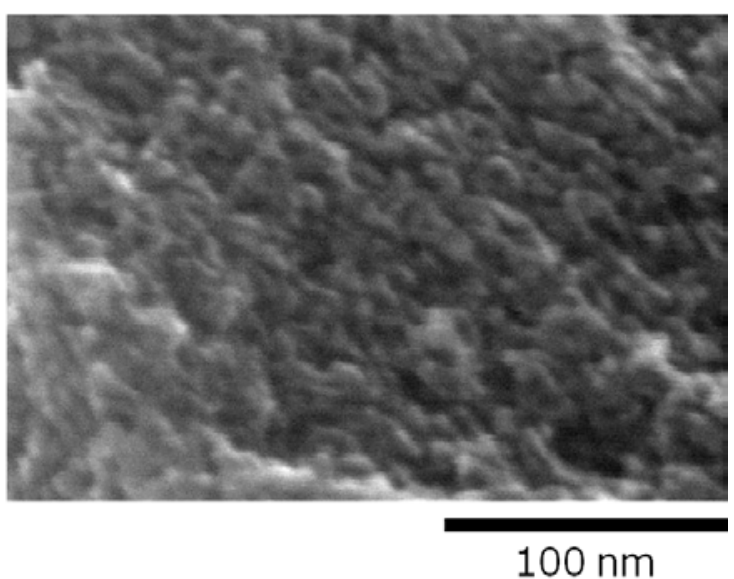

Figure S3. SEM images of nanoporous Pd and Ni. 
Immersion of bulk Pd and Ni sheets. Figure S4 shows the MO solution after 120-h immersion of bulk Pd and Ni sheets as well as control run (without sample immersion). Bulk Pd and Ni exhibited no decoloration of MO solution.

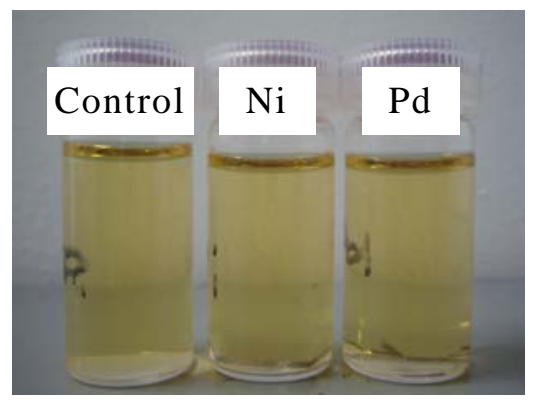

Figure S4. MO solution (initial concentration of $2 \times 10^{-5} \mathrm{~mol} / \mathrm{L}$ ) after 120 -h immersion of bulk Pd and Ni sheets. Bulk Pd and Ni exhibited no decoloration on MO solution.

XPS analyses. Figure S5 shows the X-ray photoelectron spectra of nanoporous Au (sample 1) before and after MO decoloration. The Au 4f peaks were not shifted by the decoloration, indicating that Au complex with the dye does not form.

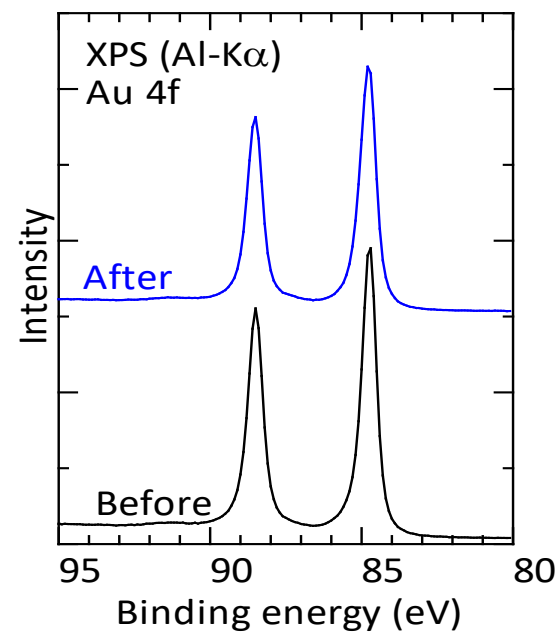

Figure S5. X-ray photoelectron spectra of nanoporous Au (sample 1) before and after MO decoloration. 